\title{
Layer regrouping for water-flooded commingled reservoirs at a high water-cut stage
}

\author{
Chuan-Zhi Cui ${ }^{1} \cdot$ Jian-Peng Xu${ }^{1} \cdot$ Duan-Ping Wang ${ }^{2} \cdot$ Zhi-Hong Liu ${ }^{2} \cdot$ \\ Ying-song Huang ${ }^{2}$ Z Zheng-Ling Geng ${ }^{3}$
}

Received: 27 November 2014/Published online: 19 April 2016

(c) The Author(s) 2016. This article is published with open access at Springerlink.com

\begin{abstract}
Layer regrouping is to divide all the layers into several sets of production series according to the physical properties and recovery percent of layers at high water-cut stage, which is an important technique to improve oil recovery for high water-cut multilayered reservoirs. Different regroup scenarios may lead to different production performances. Based on unstable oil-water flow theory, a multilayer commingled reservoir simulator is established by modifying the production split method. Taking into account the differences of layer properties, including permeability, oil viscosity, and remaining oil saturation, the pseudo flow resistance contrast is proposed to serve as a characteristic index of layer regrouping for high water-cut multilayered reservoirs. The production indices of multilayered reservoirs with different pseudo flow resistances are predicted with the established model in which the data are taken from the Shengtuo Oilfield. Simulation results show that the pseudo flow resistance contrast should be less than 4 when the layer regrouping is implemented. The K-means clustering method, which is based on the objective function, is used to automatically carry out the layer regrouping process according to pseudo flow resistances. The research result is applied to the IV-VI sand groups of the second member of the Shahejie Formation in the
\end{abstract}

Chuan-Zhi Cui

cuichuanzhi@126.com

1 College of Petroleum Engineering, China University of Petroleum, Qingdao 266580, Shandong, China

2 Exploration and Development Research Institution, Shengli Oilfield of SINOPEC, Dongying 257015, Shandong, China

3 Center for Educational Development, China University of Petroleum, Qingdao 266580, Shandong, China

Edited by Yan-Hua Sun
Shengtuo Oilfield, a favorable development performance is obtained, and the oil recovery is enhanced by $6.08 \%$.

Keywords Water-flooded reservoirs - Layer regrouping . Flow resistance $\cdot$ High water cut $\cdot$ Reservoir simulation

\section{Introduction}

For multilayer commingled reservoirs, the difference in oil recovery among different layers will become increasingly larger along the development process due to the interlayer heterogeneity (Ehlig-Economides and Joseph 1987; Jackson and Banerjee 2000). Layer regrouping is to divide all the layers into several sets of production series according to the physical properties and recovery percent of layers, which is an important technique to eliminate the differences in oil recovery of multilayered reservoirs at a high water-cut stage (Shi et al. 2006; Cui and Zhao 2010; Hu et al. 2010). The current research about layer regrouping is mostly focused on technical limits using the ordinary static parameters (Fu et al. 2002; Zhang et al. 2005; Chen et al. 2007; Liu et al. 2007). Chen et al. (2007) proposed that the principles of layer regrouping are that the permeability contrast (defined as a ratio of maximum to minimum permeability in the same development unit) should be less than 10, the layer number should be no more than 10 in the same development unit, and the thickness of the commingled production layers should be less than $20 \mathrm{~m}$. In the Lasaxing oilfield, the layer permeability contrast ( $\mathrm{max} / \mathrm{min}$ permeability ratio) is suggested to be around 2.5 (Fu et al. 2002). However, the reservoir permeability, oil viscosity, and oil saturation change along with the reservoir development (Sun et al. 1996; Zhang et al. 1997; Li et al. 2009), and there are many factors influencing the production performance of layer regrouping. 
Conventional indexes and technical limits of layer regrouping cannot meet the current demand at the high water-cut stage, and therefore, it is necessary to propose a new comprehensive index and limit for layer regrouping.

The existing methods of layer regrouping are usually based on the weighting of parameters to achieve a comprehensive index by a fuzzy evaluation, and then layer regrouping is conducted via clustering (Wang and Zhang 2001; Geng et al. 2006; Bao et al. 2010). However, the weightings of parameters are usually assigned on the basis of development experience and discussion among experts, so they are not objective enough.

Numerical reservoir simulation is usually used to study the technical limits of layer regrouping and to predict the development indexes of multilayered reservoirs (Lang 1991; Cheng et al. 2004; Mallison et al. 2004; Bokhari and Islam 2005; Jiang et al. 2006; Mustafiz and Islam 2008; Kasiri and Bashiri 2010). However, this method showed a significant deficiency in simulating multilayer commingled reservoirs at the high water-cut stage. There are marked differences between simulation results and actual measured data of the absorption rate in each layer (Ji et al. 2009). In the development of water-flooded reservoirs, interference exists objectively among different oil layers. The interlayer interference increases the water absorption capacity of high permeable layers and decreases that of low permeable ones. The water absorption capacity of the high permeable layers becomes stronger and stronger, and that of the low permeable layer becomes weaker and weaker. Simulation results obtained from the conventional numerical simulators cannot actually reflect the situation mentioned above at the high water-cut stage. The time-varying characteristics of permeability and oil viscosity are not considered in the current reservoir simulators (Wolcott et al. 1996; Choi et al. 1997; Vaziri et al. 2002; Maschio and Jose Schiozer 2003; Bhambri and Mohanty 2008; Lolon et al. 2008). Therefore, it is necessary to establish a numerical simulator for a multilayer commingled reservoir which can reflect the actual interlayer differences at the high water-cut stage.

In this paper, a new comprehensive characteristic index of layer regrouping and a method for automatic layer regrouping is presented. A new numerical simulator was also established. The data from the second member of the Shahejie Formation in the second district of the Shengtuo Oilfield were used in the calculation of the model and in the layer regrouping to validate the effectiveness of this technique.

\section{Simulation of multilayer commingled reservoirs at the high water-cut stage}

We assume that one production unit consists of $n$ single layers varying in permeability, thickness, porosity, crude oil viscosity, etc. Two-phase flow of oil and water exists in each layer, and the fluid flow follows Darcy's law. Both rock and fluids are slightly compressible, and we assume that no vertical flow occurs between layers. The influence of capillary force and gravity is ignored. Thus, considering the time-varying characteristics of the reservoir permeability and crude oil viscosity, a mathematic model for injection-production allocation in a multilayer commingled reservoir is established.

For convenience, the fluid flow in the multilayer model is regarded as a combination of one-dimensional one-way flow in $n$ layers. All layers are linked through an oil well and a water well. The method for allocating the production rate for each layer is improved, and the water adsorption rate or liquid production rate of a single layer is calculated. The pressure, oil saturation distribution, and production indices of each layer are calculated. The production indices of each layer in the same production unit at the same moment are added up. Thus, the production indices of one production unit can be obtained.

\subsection{Mathematical model}

\section{(1) Differential equations}

The differential equations describing one-dimensional flow of the oil and water phases are as follows:

Oil phase:

$$
-\frac{\partial}{\partial x}\left(\rho_{\mathrm{o}} v_{\mathrm{ox}}\right)+q_{\mathrm{o}}=\frac{\partial}{\partial t}\left(\rho_{\mathrm{o}} \phi S_{\mathrm{o}}\right) .
$$

Water phase:

$$
-\frac{\partial}{\partial x}\left(\rho_{\mathrm{w}} v_{\mathrm{w} x}\right)+q_{\mathrm{w}}=\frac{\partial}{\partial t}\left(\rho_{\mathrm{w}} \phi S_{\mathrm{w}}\right) .
$$

\section{(2) Motion equation}

The motion equations of oil and water phases are as follows:

Oil phase:

$$
v_{\mathrm{o} x}=-\frac{k k_{\mathrm{ro}} \partial p}{\mu_{\mathrm{o}} \partial x} .
$$

Water phase:

$$
v_{\mathrm{w} x}=-\frac{k k_{\mathrm{rw}} \partial p}{\mu_{\mathrm{w}} \partial x} .
$$

\section{(3) Auxiliary equation}

The auxiliary equation is the saturation equation:

$$
S_{\mathrm{o}}+S_{\mathrm{w}}=1 \text {. }
$$

In the above formulas, $\rho, v, S, q, \mu$, and $k_{\mathrm{r}}$ represent density, flow velocity, saturation, production rate, viscosity, and relative permeability, respectively; $k$ is the absolute 
permeability; $p$ is the formation pressure; $\phi$ is porosity; and $x$ is the flow direction. Subscripts o and w represent the oil and water phases, respectively.

\subsection{The solution to the model}

\subsubsection{Solution method for the mathematical model}

The finite difference method, IMPES, is used to solve the equations. In the computation of each time step, what are needed are the following: the water saturation of each grid at the last time step is used to achieve the water cut by using the fractional flow equation; the changed permeability and crude oil viscosity of each grid are obtained according to the rules that the permeability and viscosity change along with the water cut; and the water adsorption rate and the liquid production rate at each layer are calculated. A program is made to realize the solution process.

\subsubsection{Introduction of time-varying parameters}

The changes of permeability and crude oil viscosity along with the water cut are introduced into the model. Cui and Zhao (Cui and Zhao 2004) reported the changes of permeability and crude oil viscosity along with the water cut in the second member of the Shahejie Formation in the second district of the Shengtuo Oilfield. The expression describing the permeability multiplier changing with the water cut is given by

$k_{\mathrm{c}}=1.0733+0.0034 f_{\mathrm{w}}$,

and the crude oil viscosity changing with water cut may be described by

$\mu_{\mathrm{o}}=\mu_{\mathrm{oi}} \mathrm{e}^{0.0122 f_{\mathrm{w}}}$,

where $f_{\mathrm{w}}$ is the water cut, $\%$; $k_{\mathrm{c}}$ is the permeability multiplier; $\mu_{\mathrm{oi}}$ is the initial viscosity of the formation crude oil, and $\mu_{\mathrm{oi}}$ is equal to $18 \mathrm{mPa} \mathrm{s}$ in the second district of the Shengtuo Oilfield.

The relationships of the changes in permeability and oil viscosity with the water cut may be different in different reservoirs. The different relationships can lead to different calculation results. In this paper, Eqs. (6) and (7) are used in the calculation.

\subsubsection{Allocation method for the water injection rate at each layer}

In conventional numerical simulation, when the liquid production rate or the water injection rate is fixed, injectionproduction allocation at each layer is based on the parameters of the grids which the oil and water wells are located in, without considering the influence of the flow resistance from the water well to the oil well. In this paper, the flow resistance in each layer between the water and oil wells is taken into consideration in the rate allocation at each layer.

If there are $n$ layers in one set of production series, and it is one-dimensional flow from the injector to the producer, each layer is discretized into $m$ grids. The flow resistance of the $k$ th layer is expressed as

$R_{k}=\sum_{i=1}^{m}\left[\frac{d x}{A} \times \frac{1}{k\left(k_{\mathrm{ro}} / \mu_{\mathrm{o}}+k_{\mathrm{rw}} / \mu_{\mathrm{w}}\right)}\right]_{i}$

If $Q_{\mathrm{N}}$ is the total water injection rate of the water well in one production unit, the water injection rate of the $k$ th layer is

$Q_{\mathrm{N} k}=\left(\frac{1}{R_{k}} / \sum_{j=1}^{n} \frac{1}{R_{j}}\right) Q_{\mathrm{N}}$

Similarly, the liquid production rate of each layer can be obtained. The oil production rate and the water production rate of one well at the $k$ th layer are allocated according to the water and oil mobility of the grid where the well is located, and the expressions are

$$
\left\{\begin{array}{c}
Q_{\mathrm{o} k}=\left(\frac{\lambda_{\mathrm{mo}}}{\lambda_{\mathrm{mo}}+\lambda_{\mathrm{mw}}}\right)_{k} Q_{\mathrm{l} k} \\
Q_{\mathrm{w} k}=Q_{\mathrm{l} k}-Q_{\mathrm{o} k}
\end{array}\right.
$$

where $\lambda_{\mathrm{mo}}$ and $\lambda_{\mathrm{mw}}$ represent the oil mobility and water mobility, respectively; $Q_{\mathrm{o} k}, Q_{\mathrm{w} k}$, and $Q_{\mathrm{l} k}$ represent the oil production rate, water production rate, and the liquid production rate at the $k$ th layer, respectively.

\subsubsection{Analysis of calculation results}

In a case study, the oil-producing zone is composed of two layers with different permeability. When the permeability contrast is 3,5 , and 12 , respectively, the water injection rate for each layer, obtained from the conventional reservoir simulation, is shown in Fig. 1. According to Fig. 1, the difference in the allocation proportion of the water injection rate between two layers increases at the early stage, but at the later stage, the difference tends to decrease. This is not in accordance with the field situation. The reason is that, in the conventional numerical simulation, the allocation results are calculated using the parameters of the grids where the well is located without consideration of the oil saturation distribution from the injector to the producer.

Figure 2 shows allocation results calculated from the reservoir simulation model built in this paper. In Fig. 2, from the early to mid-stage, the difference in the allocation proportion between two layers keeps increasing. In the later stage, the difference in the allocation proportion tends to be stable. This is in accordance with the actual case and proves the validity of the model. 


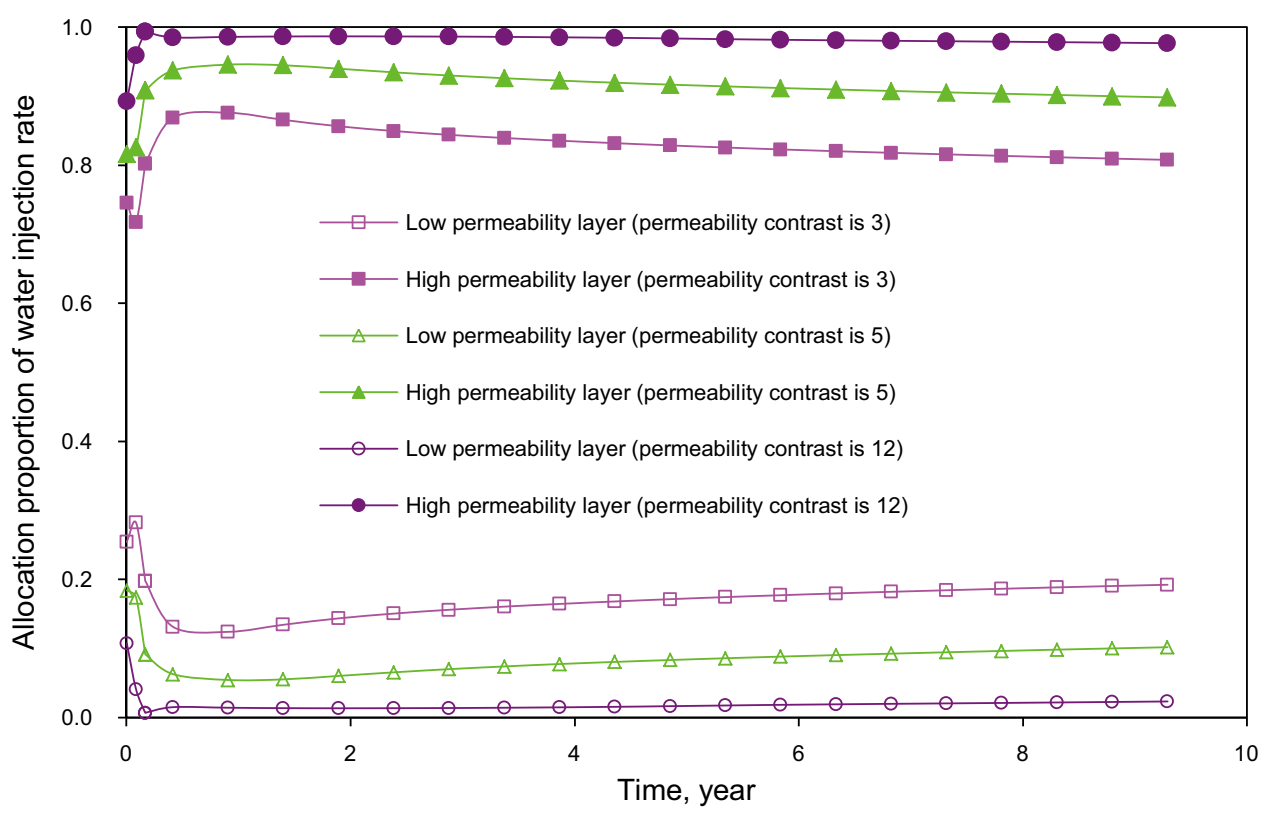

Fig. 1 Calculation results from the conventional reservoir simulator

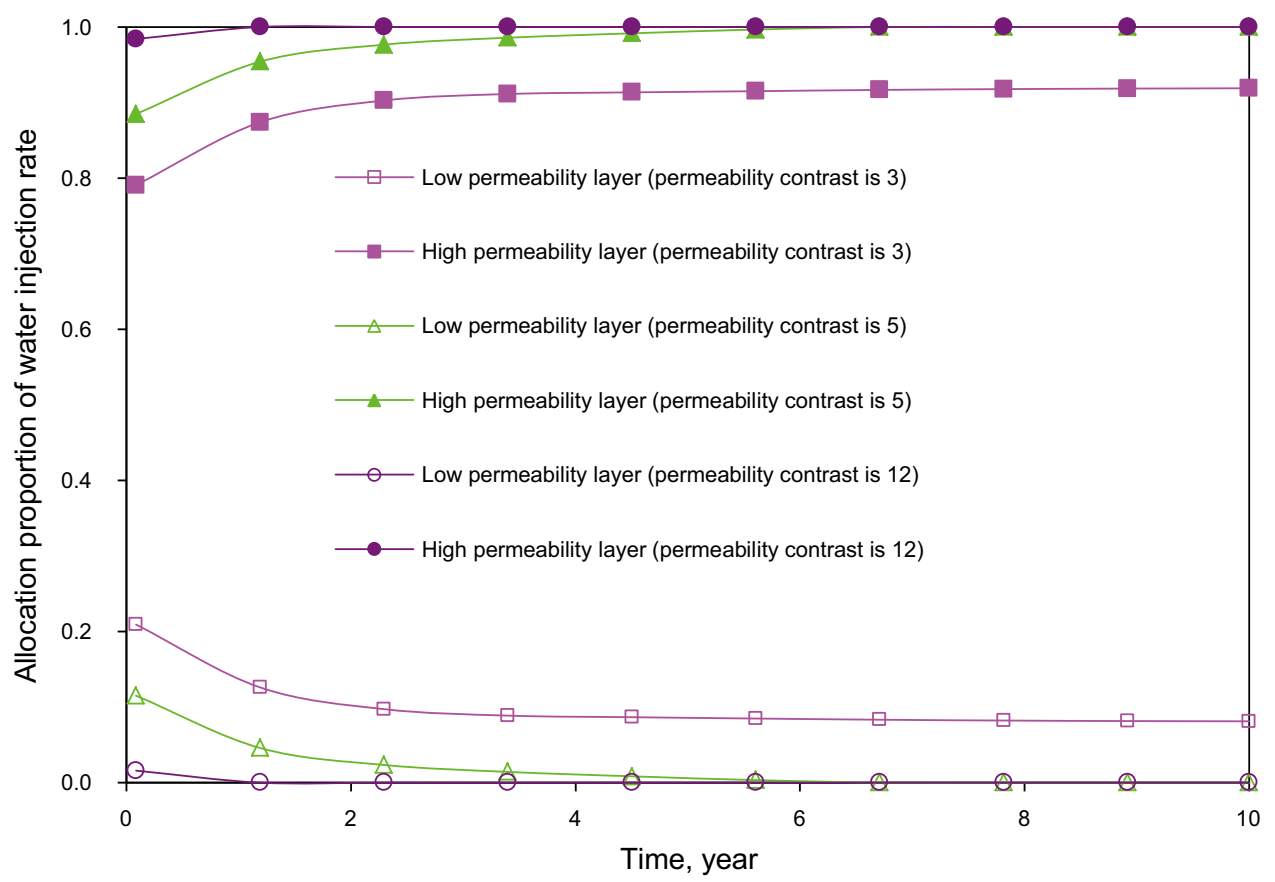

Fig. 2 Calculation results from the reservoir simulation model built in this paper

\section{The comprehensive index and technical limit of layer regrouping}

\subsection{The comprehensive index of layer regrouping}

For high water-cut reservoirs, representation indexes of layer regrouping, such as permeability contrast and crude oil viscosity contrast, cannot meet the needs of layer regrouping. In this paper, the pseudo flow resistance contrast is taken as a comprehensive index of layer regrouping at the high water-cut stage.

When oil and water phases flow simultaneously, the liquid production rate is derived from Darcy's law: 
$Q_{\mathrm{t}}=\left(\frac{k_{\mathrm{o}}}{\mu_{\mathrm{o}}\left(f_{\mathrm{w}}\right)}+\frac{k_{\mathrm{w}}}{\mu_{\mathrm{w}}}\right) A \frac{\Delta p}{L}=\frac{\Delta p}{\frac{\mu_{\mathrm{o}}\left(f_{\mathrm{w}}\right) \mu_{\mathrm{w}}}{k_{\mathrm{o}} \mu_{\mathrm{w}}+k_{\mathrm{w}} \mu_{\mathrm{o}}\left(f_{\mathrm{w}}\right)} \frac{L}{A}}=\frac{\Delta p}{R}$.

The pseudo flow resistance is defined as

$R^{\prime}=\frac{\mu_{\mathrm{o}}\left(f_{\mathrm{w}}\right) \mu_{\mathrm{w}}}{k_{\mathrm{o}} \mu_{\mathrm{w}}+k_{\mathrm{w}} \mu_{\mathrm{o}}\left(f_{\mathrm{w}}\right)}$.

Equation (12) shows that the pseudo flow resistance is related to the crude oil viscosity and effective permeability of oil and water phases. The effective permeability reflects the effect of absolute permeability and remaining oil saturation, and the expressions are given by

$k_{\mathrm{o}}=k\left(f_{\mathrm{w}}\right) k_{\mathrm{ro}}\left(S_{\mathrm{w}}\right), k_{\mathrm{w}}=k\left(f_{\mathrm{w}}\right) k_{\mathrm{rw}}\left(S_{\mathrm{w}}\right)$.

The pseudo flow resistance contrast is a ratio of maximum to minimum pseudo flow resistance among layers in the same one set of production series.

\subsection{The technical limit of layer regrouping}

An 18-layer commingled reservoir model is established to study the technical limit of layer regrouping at the high water-cut stage. The initial permeability values of 18 layers are listed in Table 1. The producer-injector spacing is $300 \mathrm{~m}$, the crude oil viscosity is $18 \mathrm{mPa}$ s, and the porosity is 0.28 . The reservoir simulation model built above is used for calculations. When the water cut is $95 \%$, the conditions of each layer are shown in Table 1.

This research on layer regrouping is conducted when the comprehensive water cut is $95 \%$. Two layers with different pseudo flow resistance are recombined separately, and the production continues until the water cut is $98 \%$. The curve between the oil recovery factor (the proportion of the oil in a reservoir which is recovered) and the pseudo flow resistance contrast is shown in Fig. 3. Figure 4 shows the curves between cumulative water-oil ratio and pseudo flow resistance contrast when the commingled production time is $5,10,15,20$, and 25 years respectively.

Figures 3 and 4 indicate that the production performance becomes worse when the pseudo flow resistance contrast increases. When the pseudo flow resistance contrast is greater than 4 , the oil recovery dramatically decreases and the cumulative water-oil ratio increases rapidly. Therefore, it is appropriate to limit pseudo flow resistance contrast within 4 in layer regrouping at the high water-cut stage.

\section{Optimizing method of layer regrouping}

If there are many layers in one reservoir, there may be many different recombination scenarios of layers even we set the pseudo flow resistance contrast less than 4 . So it is
Table 1 Parameters of each layer at water cut $95 \%$

\begin{tabular}{llcll}
\hline $\begin{array}{l}\text { Layers } \\
\text { number }\end{array}$ & $\begin{array}{l}\text { Initial } \\
\text { permeability, } \\
10^{-3} \mu \mathrm{m}^{2}\end{array}$ & $\begin{array}{l}\text { Water } \\
\text { cut, } \%\end{array}$ & $\begin{array}{l}\text { Oil } \\
\text { recovery, } \%\end{array}$ & $\begin{array}{l}\text { Pseudo flow } \\
\text { resistance, } \\
\text { mPa s/ } \mu \mathrm{m}^{2}\end{array}$ \\
\hline 1 & 200 & 0 & 0.03 & 46.59 \\
2 & 400 & 7.34 & 2.33 & 22.57 \\
3 & 500 & 23.57 & 7.89 & 16.33 \\
4 & 600 & 46.55 & 16.39 & 11.00 \\
5 & 700 & 75.71 & 20.15 & 7.82 \\
6 & 800 & 84.17 & 22.27 & 6.11 \\
7 & 900 & 87.86 & 23.84 & 5.02 \\
8 & 1000 & 89.22 & 25.2 & 4.22 \\
9 & 1100 & 90.83 & 26.45 & 3.61 \\
10 & 1200 & 92.28 & 27.55 & 3.14 \\
11 & 1400 & 94.39 & 29.35 & 2.48 \\
12 & 1600 & 95.36 & 30.81 & 2.04 \\
13 & 1800 & 95.56 & 32.2 & 1.71 \\
14 & 2000 & 95.97 & 33.58 & 1.45 \\
15 & 2200 & 96.46 & 34.87 & 1.24 \\
16 & 2400 & 96.91 & 36.06 & 1.08 \\
17 & 2600 & 97.29 & 37.15 & 0.96 \\
18 & 2800 & 97.58 & 38.14 & 0.85 \\
\hline & & & &
\end{tabular}

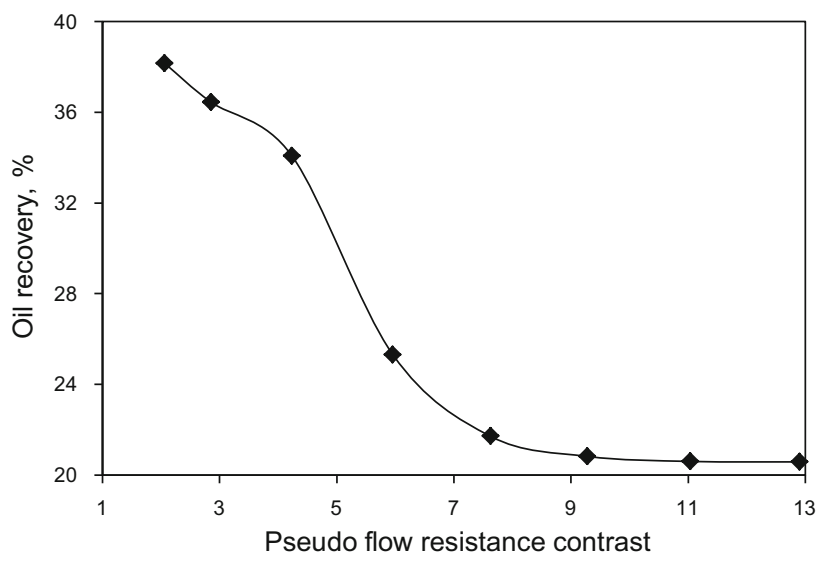

Fig. 3 Curve between oil recovery and pseudo flow resistance contrast

required to find an optimal one to obtain the highest oil recovery.

Based on the pseudo flow resistance of one single layer, using the K-means clustering method (Wang and Niu 2004; Kong et al. 2004), layer regrouping is carried out to obtain the optimal production performance. This is the basic principle of the K-means clustering method. Assume that there are $n$ samples $\left(x_{1}, x_{2}, \ldots, x_{n}\right)$, and they are classified into $p$ types: $\left(C_{1}, C_{2}, \ldots, C_{p}\right)$. Assume that the number of the $i$ th type is $N_{i}$, and the mean of the types is $\left(m_{1}, m_{2}, \ldots, m_{p}\right)$, and then $m_{i}=\frac{1}{N_{i}} \sum_{i=1}^{N_{i}} x_{i}(i=1,2$, 


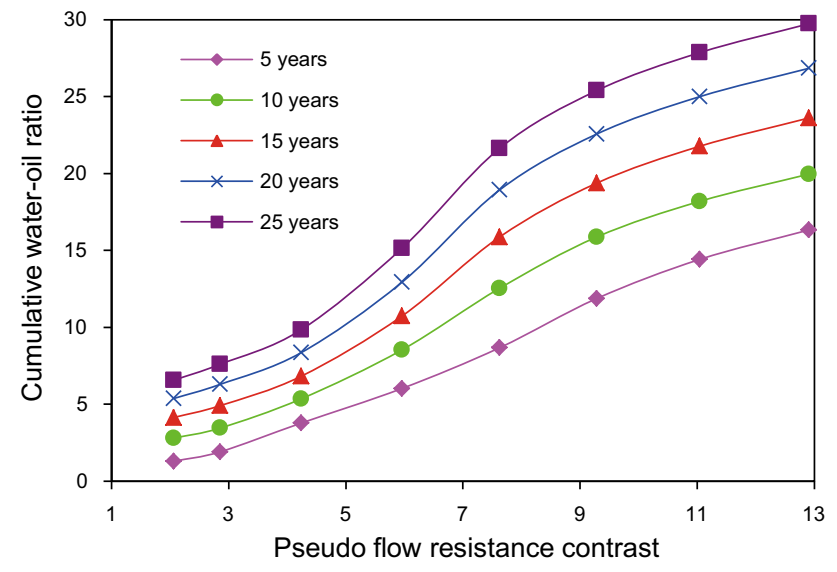

Fig. 4 Curves between cumulative water-oil ratio and pseudo flow resistance contrast

$\ldots, p)$. K-means clustering is on the basis of the least square method, and its object function is

$\min J=\sum_{i=1}^{p} \sum_{j=1}^{N_{i}}\left\|x_{j}-m_{i}\right\|^{2}$

In the layer regrouping, supposing that the commingled reservoir of $n$ layers comes to high water-cut stage, $p$ sets of production series are divided according to the pseudo flow resistance of each layer. $p$ single layers are randomly selected to be the initial center of the $p$ sets of production series, and the rest of layers are assigned into the production series where the nearest production series center locates. This is the initial division of the $p$ sets of production series. Calculation of new centers is done to the newly allocated production series, and then the allocation of other layers is continued. After several cycles of iteration, the centers of the $p$ sets of production series do not change any more, which means that all single layers have been allocated to their own production series. Correct clustering leads to a convergence function; otherwise, the iteration continues. A program is made to realize the optimal process.

\section{Case analysis}

The IV-VII sand groups of the second member of the Shahejie Formation in the second district of the Shengtuo Oilfield are located at the southwest of the structural high position of the Shengtuo Oilfield and are delta plain sedimentary subfaces. The IV-VI sand groups consist of 18 oilbearing layers. Among them, there are 5 layers in the 4th sand group, 6 layers in the 5th sand group, and 7 layers in the 6th sand group. These sand groups have been put into production as one production series since 1975, and a high water cut was observed, and the oil recovery percent (a ratio of the produced oil to OIPP) was $35.5 \%$. Table 2 shows the parameters and the calculation results of pseudo flow resistance of each layer.

Table 3 shows the recombination results from the K-means clustering method. When these layers are

Table 2 Parameters of the IV-VI sand groups in the Shengtuo Oilfield

\begin{tabular}{|c|c|c|c|c|c|c|}
\hline $\begin{array}{l}\text { Sublayer } \\
\text { name }\end{array}$ & $\begin{array}{l}\text { Permeability, } \\
10^{-3} \mu \mathrm{m}^{2}\end{array}$ & Net thickness, m & Porosity & $\begin{array}{l}\text { Remaining } \\
\text { oil saturation }\end{array}$ & $\begin{array}{l}\text { Remaining } \\
\text { reserves, } 10^{4} \mathrm{t}\end{array}$ & $\begin{array}{l}\text { Pseudo flow } \\
\text { resistance, } \mathrm{mPa} \mathrm{s} / \mu \mathrm{m}^{2}\end{array}$ \\
\hline $\mathrm{S}_{2} 4^{1}$ & 3041.5 & 3.44 & 0.274 & 0.445 & 17.88 & 1.252 \\
\hline $\mathrm{S}_{2} 4^{2}$ & 3796.0 & 3.09 & 0.286 & 0.421 & 15.69 & 0.905 \\
\hline $\mathrm{S}_{2} 4^{3}$ & 1084.0 & 1.37 & 0.278 & 0.574 & 5.08 & 6.525 \\
\hline $\mathrm{S}_{2} 4^{4}$ & 925.0 & 1.97 & 0.271 & 0.587 & 7.28 & 8.538 \\
\hline $\mathrm{S}_{2} 4^{5}$ & 1427.9 & 2.64 & 0.261 & 0.534 & 7.12 & 4.093 \\
\hline $\mathrm{S}_{2} 5^{1}$ & 1100.9 & 0.86 & 0.276 & 0.571 & 0.93 & 6.278 \\
\hline $\mathrm{S}_{2} 5^{2}$ & 2790.4 & 1.08 & 0.267 & 0.453 & 3.68 & 1.415 \\
\hline $\mathrm{S}_{2} 5^{3}$ & 1329.7 & 2.06 & 0.277 & 0.550 & 9.97 & 4.681 \\
\hline $\mathrm{S}_{2} 5^{4}$ & 1445.6 & 2.38 & 0.270 & 0.537 & 6.11 & 4.093 \\
\hline $\mathrm{S}_{2} 5^{5}$ & 3512.0 & 3.36 & 0.288 & 0.432 & 17.26 & 1.025 \\
\hline $\mathrm{S}_{2} 5^{6}$ & 1735.1 & 1.10 & 0.270 & 0.512 & 1.68 & 3.022 \\
\hline $\mathrm{S}_{2} 6^{1}$ & 1581.6 & 1.44 & 0.288 & 0.534 & 5.52 & 3.695 \\
\hline $\mathrm{S}_{2} 6^{2}$ & 615.8 & 1.73 & 0.230 & 0.609 & 6.55 & 14.769 \\
\hline $\mathrm{S}_{2} 6^{3}$ & 903.7 & 0.89 & 0.255 & 0.583 & 1.76 & 8.432 \\
\hline $\mathrm{S}_{2} 6^{4}$ & 1276.8 & 1.34 & 0.279 & 0.556 & 4.71 & 4.994 \\
\hline $\mathrm{S}_{2} 6^{5}$ & 2767.1 & 1.61 & 0.275 & 0.458 & 5.08 & 1.458 \\
\hline $\mathrm{S}_{2} 6^{6}$ & 1903.7 & 1.49 & 0.284 & 0.506 & 5.49 & 2.681 \\
\hline $\mathrm{S}_{2} 6^{7}$ & 1443.0 & 2.54 & 0.268 & 0.536 & 13.71 & 4.084 \\
\hline
\end{tabular}


Table 3 Layer regrouping programs of the IV-VI sand groups in the Shengtuo Oilfield

\begin{tabular}{|c|c|c|c|}
\hline Layer regrouping program & Layer names & $\begin{array}{l}\text { Pseudo flow } \\
\text { resistance contrast }\end{array}$ & $\begin{array}{l}\text { Remaining } \\
\text { reserves, } 10^{4} \mathrm{t}\end{array}$ \\
\hline One set & All layers & 16.327 & 135.51 \\
\hline \multirow[t]{2}{*}{ Two sets } & $\mathrm{S}_{2} 4^{3}, \mathrm{~S}_{2} 4^{4}, \mathrm{~S}_{2} 5^{1}, \mathrm{~S}_{2} 6^{2}, \mathrm{~S}_{2} 6^{3}$ & 2.352 & 21.60 \\
\hline & $\begin{array}{l}\mathrm{S}_{2} 4^{1}, \mathrm{~S}_{2} 4^{2}, \mathrm{~S}_{2} 4^{5}, \mathrm{~S}_{2} 5^{2}, \mathrm{~S}_{2} 5^{3}, \mathrm{~S}_{2} 5^{4}, \mathrm{~S}_{2} 5^{5}, \mathrm{~S}_{2} 5^{6} \\
\mathrm{~S}_{2} 6^{1}, \mathrm{~S}_{2} 6^{4}, \mathrm{~S}_{2} 6^{5}, \mathrm{~S}_{2} 6^{6}, \mathrm{~S}_{2} 6^{7}\end{array}$ & 5.521 & 113.90 \\
\hline \multirow[t]{3}{*}{ Three sets } & $\mathrm{S}_{2} 4^{4}, \mathrm{~S}_{2} 6^{2}, \mathrm{~S}_{2} 6^{3}$ & 1.752 & 15.59 \\
\hline & $\mathrm{S}_{2} 4^{1}, \mathrm{~S}_{2} 4^{2}, \mathrm{~S}_{2} 5^{2}, \mathrm{~S}_{2} 5^{5}, \mathrm{~S}_{2} 5^{6}, \mathrm{~S}_{2} 6^{5}, \mathrm{~S}_{2} 6^{6}$ & 3.341 & 66.76 \\
\hline & $S_{2} 4^{3}, S_{2} 4^{5}, S_{2} 5^{1}, S_{2} 5^{3}, S_{2} 5^{4}, S_{2} 6^{1}, S_{2} 6^{4}, S_{2} 6^{7}$ & 1.766 & 53.16 \\
\hline \multirow[t]{4}{*}{ Four sets } & $\mathrm{S}_{2} 6^{2}$ & 1.000 & 6.55 \\
\hline & $\mathrm{S}_{2} 4^{3}, \mathrm{~S}_{2} 4^{4}, \mathrm{~S}_{2} 5^{1}, \mathrm{~S}_{2} 6^{3}$ & 1.360 & 15.05 \\
\hline & $S_{2} 4^{1}, S_{2} 4^{2}, S_{2} 5^{2}, S_{2} 5^{5}, S_{2} 6^{5}$ & 1.612 & 59.59 \\
\hline & $S_{2} 4^{5}, S_{2} 5^{3}, S_{2} 5^{4}, S_{2} 6^{5}, S_{2} 6^{1}, S_{2} 6^{4}, S_{2} 6^{6}, S_{2} 6^{7}$ & 1.862 & 54.32 \\
\hline
\end{tabular}

recombined to two sets of production series, the pseudo flow resistance contrast of one set is greater than 4 . When these layers are recombined to three or four production series, the pseudo flow resistance contrasts are smaller than 4, which meet the technical limit of layer regrouping. According to the requirement of individual-well control reserves at the high water-cut stage (Wang and Niu 2004), the remaining reserves in $\mathrm{S}_{2} 6^{2}$ layer in the four sets of production series are only $6.552 \times 10^{4}$ tons, and it is not economical to set it as one set of production series. Therefore, the 4th-6th sand groups are recombined to three sets of production series.

After layer regrouping, the development indexes were predicted with the reservoir simulation model built above (Fig. 5). Compared with the scenario without layer regrouping (one set of production series), the oil recovery of two sets of production series increases by $2.14 \%$, and the oil recovery of three sets of production series increases by $6.08 \%$. Hence, recombination of three sets of production series can achieve better performance and are recommended.

\section{Conclusions}

(1) A numerical simulator was established for a multilayer commingled reservoir, which considers the changes of permeability and oil viscosity during oil production. A method for allocating the water injection rate and the liquid production rate of wells at each layer was modified. The results of the simulator can actually reflect the characteristics of fluid flow in different producing layers in the multilayer commingled reservoir at the high water-cut stage.

(2) The pseudo flow resistance contrast was proposed to be a characteristic index of layer regrouping at the high water-cut stage, which considers each single

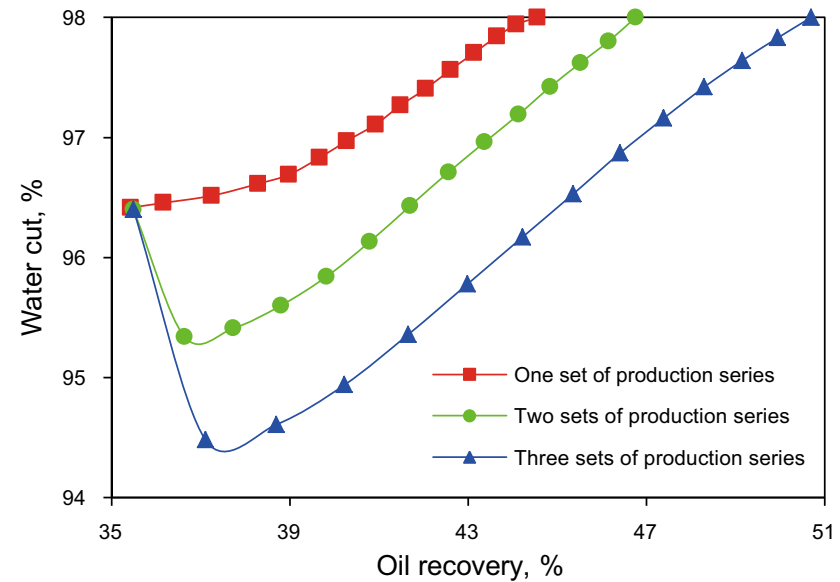

Fig. 5 Curves between water cut and oil recovery

layer's permeability, crude oil viscosity, and the remaining oil saturation. By analyzing the simulation results from the numerical simulator built in this paper, the pseudo flow resistance contrast in one set of production series should be controlled within 4 in layer regrouping at the high water-cut stage. A Kmeans clustering method was used to implement the automatic optimization of layer regrouping.

(3) The limit of the pseudo flow resistance contrast in this paper was obtained through the data from the second district of the Shengtuo Oilfield. The limit may be different in different reservoirs. In the layer regrouping at the high water-cut stage, in addition to the pseudo flow resistance contrast, the remaining reserves, well pattern, well spacing, etc., are needed to be considered.

Acknowledgments This work was supported by the Program for Changjiang Scholars and Innovative Research Team in University 
(IRT1294) and the China National Science and Technology Major Projects (Grant No: 2016ZX05011).

Open Access This article is distributed under the terms of the Creative Commons Attribution 4.0 International License (http://crea tivecommons.org/licenses/by/4.0/), which permits unrestricted use, distribution, and reproduction in any medium, provided you give appropriate credit to the original author(s) and the source, provide a link to the Creative Commons license, and indicate if changes were made.

\section{References}

Bao JW, Song XM, Ye JG, et al. Recombination of layer series of development in a high water-cut oil field. Xinjiang Pet Geol. 2010;31(3):291-4 (in Chinese).

Bhambri P, Mohanty KK. Two and three-hydrocarbon phase streamline-based compositional simulation of gas injections. J Pet Sci Eng. 2008;62(1):16-27. doi:10.1016/j.petrol.2008.06.003.

Bokhari K, Islam MR. Improvement in the time accuracy of numerical methods in petroleum engineering problems: a new combination. Energy Sources. 2005;27(1-2):45-60. doi:10.1080/ 00908310490448109.

Chen MF, Jiang HQ, Zeng YX. A study of maximum/minimum permeability ratio boundaries for reasonable developed-layer recombination in extremely heterogeneous reservoirs. China Offshore Oil Gas. 2007;19(5):319-22 (in Chinese).

Cheng $\mathrm{H}$, Kharghoria A, Zhong $\mathrm{H}$, et al. Fast history matching of finite difference models using streamline-derived sensitivities. In: SPE/DOE symposium on improved oil recovery, 17-21 April, Tulsa, Oklahoma; 2004. doi:10.2118/89447-PA.

Choi ES, Cheema T, Islam MR. A new dual-porosity/dual permeability model with non-Darcian flow through fractures. J Pet Sci Eng. 1997;17(3):331-44. doi:10.1016/S0920-4105(96)00050-2.

Cui CZ, Zhao XY. A numerical reservoir simulation study with the variety of reservoir parameters. J Hydrodyn. 2004;19(A):912-5 (in Chinese).

Cui CZ, Zhao XY. Method for calculating production indices of multilayer water drive reservoirs. J Pet Sci Eng. 2010;75(1):66-70. doi:10.1016/j.petrol.2010.10.003.

Ehlig-Economides CA, Joseph J. A new test for determination of individual layer properties in a multilayered reservoir. SPE Form Eval. 1987;2(3):261-83. doi:10.2118/14167-PA.

Fu BZ, Kong XT, Chen ZM, et al. Principles for combining series of polymer flooding in Lamadian-Saertu-Xingshugang oilfields. Pet Geol Oilfield Dev Daqing. 2002;21(6):51-4 (in Chinese).

Geng ZL, Jiang HQ, Sun MR, et al. Model of rhythmite reconstruction in the reservoirs with extra high water cut. J Oil Gas Technol. 2006;28(6):102-6 (in Chinese).

Hu DD, Tang W, Chang YW, et al. A study for redevelopment trends after polymer flooding and its field application in La-sa-xing oilfield. In: International oil and gas conference and exhibition in China, 8-10 June, Beijing, China; 2010. doi:10.2118/130903MS.

Jackson RR, Banerjee R. Advances in multilayer reservoir testing and analysis using numerical well testing and reservoir simulation. In: SPE annual technical conference and exhibition, 1-4 October, Dallas, Texas; 2000. doi:10.2118/62917-MS.

Ji BY, Zhao GZ, Li H, et al. Multidisciplinary integrated reservoir research methods and application. Beijing: Petroleum Industry Press; 2009 (in Chinese).
Jiang HQ, Yao J, Jiang RZ. Principles and methods of reservoir engineering. Dongying: China University of Petroleum Press; 2006 (in Chinese).

Kasiri N, Bashiri A. Comparative study of different techniques for numerical reservoir simulation. Pet Sci Technol. 2010;28(5):494-503. doi:10.1080/10916460903515532.

Lang ZX. Reservoir engineering. Beijing: Petroleum Industry Press; 1991 (in Chinese).

Li H, Wang XW, Liu SL. Variation law of parameters of reservoir physical property in old oilfield. J Southwest Pet Univ (Sci Technol Ed). 2009;31(2):85-9 (in Chinese).

Liu YP, Chen YM, Yuan SB, et al. Well pattern reconstruction of a refined cyclothem in the 8th member of Es3 in fault block Tuo21. J Oil Gas Technol. 2007;29(5):116-20 (in Chinese).

Lolon E, Archer RA, Ilk D, et al. New semianalytical solutions for multilayer reservoirs. In: CIPC/SPE gas technology symposium 2008 joint conference, 16-19 June, Calgary, Alberta; 2008. doi:10.2118/114946-MS.

Kong R, Zhang GX, Shi ZS. Kernel-based K-means clustering. Comput Eng. 2004;30(11):12-3 (in Chinese).

Mallison BT, Gerritsen MG, Matringe SF. Improved mappings for streamline based simulation. In: SPE/DOE symposium on improved oil recovery, 17-21 April, Tulsa, Oklahoma; 2004. doi:10.2523/89352-MS.

Maschio C, Jose Schiozer D. A new upscaling technique based on Dykstra-Parsons coefficient: evaluation with streamline reservoir simulation. J Pet Sci Eng. 2003;40(1):27-36. doi:10.1016/ S0920-4105(03)00060-3.

Mustafiz S, Islam MR. State-of-the-art petroleum reservoir simulation. Pet Sci Technol. 2008;26(10-11):1303-29. doi:10.1080/ 10916460701834036.

Shi CF, Du QL, Zhu LH, et al. Research on remaining oil distribution and further development methods for different kinds of oil layers in Daqing oilfield at high water-cut stage. In: SPE Asia Pacific oil \& gas conference and exhibition, 11-13 September, Adelaide; 2006. doi:10.2118/101034-MS.

Sun SX, Han JW, Guo YR, et al. Laboratory experiment on physical properties of flooding sandstone in Shengtuo oilfield. J Univ Pet. 1996;20(Suppl):33-5 (in Chinese).

Vaziri HH, Xiao Y, Islam R, et al. Numerical modeling of seepageinduced sand production in oil and gas reservoirs. J Pet Sci Eng. 2002;36(1):71-86. doi:10.1016/S0920-4105(02)00264-4.

Wang J, Zhang JS. Comparing several methods of assuring weight vector in synthetic evaluation. J Hebei Univ Technol. 2001;30(2):52-7 (in Chinese).

Wang SB, Niu SW. Layer subdivision in the late high water cut stage in the complex fault block reservoirs, Dongxin oilfield. Pet Explor Dev. 2004;31(3):116-8 (in Chinese).

Wolcott DS, Kazemi H, Dean RH. A practical method for minimizing the grid orientation effect in reservoir simulation. In: SPE annual technical conference and exhibition, 6-9 Oct, Denver, Colorado; 1996. doi:10.2118/36723-MS.

Zhang HX, Liu QN, Li FQ, et al. Variations of petrophysical parameters after sandstone reservoirs watered out in Daqing oilfield. SPE Adv Technol Ser. 1997;5(1):128-39. doi:10.2118/ 30844-PA.

Zhang SM, Liu ZH, Wan HY, et al. Technical limits for pattern rearrangement in the late period of high water-cut in an uncompartmentalized oilfield. Spec Oil Gas Reserv. 2005;12(2):57-62 (in Chinese). 